\title{
LETTER
}

\section{Comparison of endotracheal intubation using direct and video laryngoscopes in the ICU}

\author{
Fu-Shan Xue*, Yi Cheng and Rui-Ping Li \\ See related research by Noppens et al., http://ccforum.com/content/16/3/R103
}

In a prospective, comparative study, Noppens and colleagues [1] demonstrated that, compared with the Macintosh direct laryngoscope (MDL), the C-MAC videolaryngoscope (C-MAC) improved laryngeal view and achieved a higher intubation success rate on first attempt in patients with predictors of difficult intubation in the ICU. In the Materials and methods, however, the authors did not mention what position the patient's head was placed during laryngoscopy. This may be unimportant for the C-MAC, which does not require the alignment of the oral, pharyngeal, and tracheal axes to visualize the glottis [2]. When using the MDL, however, the patient's head should always be in a sniffing position, which aligns the oral, pharyngeal, and laryngeal axis into more of a straight line [3]. We believe that when the laryngoscopic views with direct and video laryngoscopes are used as endpoints, negligence of this factor would have significantly underestimated the performance of the MDL, particularly in patients with predictors of difficult intubation.
In a two-year study period, endotracheal intubation was successfully performed in 113 patients using the MDL and 117 patients using the C-MAC. Of those, there were no differences in the number of intubation attempts between the two devices. Moreover, both use of alternative airway devices after failed intubation with the MDL and C-MAC devices (27 out of 140 versus 17 out of 134) and the lowest oxygen saturation during intubation did not significantly differ between the two groups. Interestingly, eight patients in whom intubation with the C-MAC failed were successfully rescued with the MDL. Thus, this study would not achieve the conclusion that the C-MAC outperforms the MDL for endotracheal intubation in the ICU patients. Two recent randomized, controlled manikin studies by emergency physicians and/ or anesthetists showed that none of five indirect laryngoscopes, including the Glidescope, C-MAC, Pentax AWS, Airtraq, and McGrath, outperformed the MDL for emergency difficult intubation $[4,5]$.

\section{Authors' response}

Ruediger R Noppens, Stephanie Geimer, Nicole Eisel, Matthias David and Tim Piepho

We thank Xue and colleagues for their interest and their comments regarding our recent work [1]. We agree that correct positioning of the patient's head during airway management is a key maneuver to facilitate endotracheal intubation. In our study the standard procedures for endotracheal intubation remained unchanged. This also included optimal positioning of the patient. Moreover, the presence of at least two healthcare professionals, with at least one senior physician, was standard for all intubations. It is self-evident, therefore, that the best position of the patient's head was chosen in all cases.

*Correspondence: fruitxue@yahoo.com.cn

Department of Anesthesiology, Plastic Surgery Hospital, Chinese Academy of Medical Sciences and Peking Union Medical College, 33 Ba-Da-Chu Road, Shi-JingShan District, Beijing, People's Republic of China 100144
After introduction of the C-MAC, eight patients were intubated using the MDL [1]. We wish to emphasize that the MDL was not used as a rescue device after failed intubation using the C-MAC video laryngoscope in these patients. Not all intubations were performed using the C-MAC in the second part of the study; some physicians decided to use the MDL for endotracheal intubation.

To our knowledge, this is the first study comparing the MDL with the C-MAC for endotracheal intubation in critically ill patients in the ICU. Our key messages are that the use of the C-MAC video laryngoscope improved visualization during endotracheal intubation and reduced the number of intubating attempts if at least one predictor for difficult intubation was present. We and others strongly believe that manikin studies alone are insufficient to reflect conditions of patients, especially in the intensive care setting [6]. 


\section{Abbreviations}

C-MAC, C-MAC videolaryngoscope; MDL, Macintosh direct laryngoscope.

\section{Competing interests}

The authors declare that they have no competing interests.

\section{Published: 27 July 2012}

\section{References}

1. Noppens RR, Geimer S, Eisle N, David M, Piepho T: Endotracheal intubation using the $\mathrm{C}^{-\mathrm{MAC}^{\circledR}}{ }^{\circledR}$ video laryngoscope or the Macintosh laryngoscope: a prospective, comparative study in the ICU. Crit Care 2012, 16:R103.

2. Niforopoulou P, Pantazopoulos I, Demestiha T, Koudouna E, Xanthos T: Videolaryngoscopes in the adult airway management: a topical review of the literature. Acta Anaesthesio/ Scand 2010, 54:1050-1061.

3. El-Orbany M, Woehlck H, Salem MR: Head and neck position for direct laryngoscopy. Anesth Analg 2011, 113:103-109.
4. Wetsch WA, Carlitscheck M, Spelten O, Teschendorf P, Hellmich M, Genzwürker HV, Hinkelbein J: Success rates and endotracheal tube insertion times of experienced emergency physicians using five video laryngoscopes: a randomised trial in a simulated trapped car accident victim. Eur J Anaesthesiol 2011, 28:849-858.

5. Wetsch WA, Spelten O, Hellmich M, Carlitscheck M, Padosch SA, Lier H, Böttiger BW, Hinkelbein J: Comparison of different video laryngoscopes for emergency intubation in a standardized airway manikin with immobilized cervical spine by experienced anaesthetists. A randomized, controlled crossover trial. Resuscitation 2012, 83:740-745.

6. Cook TM, Howes B, Wharton N: Evaluation of airway equipment: man or manikin? Anaesthesia 2011, 66:529.

doi:10.1186/cc11409

Cite this article as: Xue FS, et al:: Comparison of endotracheal intubation using direct and video laryngoscopes in the ICU. Critical Care 2012, 16:441. 